Research Article

Human and Medical Genetics

\title{
-866G/A and Ins/Del polymorphisms in the UCP2 gene and diabetic kidney disease: case-control study and meta-analysis
}

\author{
Cristine Dieter ${ }^{1,2}$ id , Taís Silveira Assmann ${ }^{3}$ id , Natália Emerim Lemos ${ }^{1,2}$ [iD, Eloísa Toscan \\ Massignam $^{1}$ iD, Bianca Marmontel de Souza ${ }^{1,2}$ iD, Andrea Carla Bauer ${ }^{1,2,4}$ [D and Daisy Crispim ${ }^{1,2}$ [id \\ ${ }^{1}$ Hospital de Clínicas de Porto Alegre, Endocrine Division, Porto Alegre, RS, Brazil. \\ ${ }^{2}$ Universidade Federal do Rio Grande do Sul, Faculdade de Medicina, Programa de Pós-Graduação em \\ Ciências Médicas: Endocrinologia, Porto Alegre, RS, Brazil. \\ ${ }^{3}$ Universidad de Navarra, Department of Nutrition, Food Science and Physiology, Pamplona, Spain. \\ ${ }^{4}$ Hospital de Clínicas de Porto Alegre, Nephrology Division, Porto Alegre, RS, Brazil.
}

\begin{abstract}
Uncoupling protein 2 (UCP2) decreases reactive oxygen species (ROS). ROS overproduction is a key contributor to the pathogenesis of diabetic kidney disease (DKD). Thus, UCP2 polymorphisms are candidate risk factors for DKD; however, their associations with this complication are still inconclusive. Here, we describe a case-control study and a meta-analysis conducted to investigate the association between UCP2 -866G/A and Ins/Del polymorphisms and DKD. The case-control study comprised 385 patients with type 1 diabetes mellitus (T1DM): 223 patients without DKD and 162 with DKD. UCP2 -866G/A (rs659366) and Ins/Del polymorphisms were genotyped by real-time PCR and conventional PCR, respectively. For the meta-analysis, a literature search was conducted to identify all studies that investigated associations between UCP2 polymorphisms and DKD in patients with T1DM or type 2 diabetes mellitus. Pooled odds ratios were calculated for different inheritance models. Allele and genotype frequencies of $-866 \mathrm{G} / \mathrm{A}$ and Ins/Del polymorphisms did not differ between T1DM case and control groups. Haplotype frequencies were also similar between groups. Four studies plus the present one were eligible for inclusion in the meta-analysis. In agreement with case-control data, the meta-analysis results showed that the -866G/A and Ins/Del polymorphisms were not associated with DKD. In conclusion, our case-control and meta-analysis studies did not indicate an association between the analyzed UCP2 polymorphisms and DKD.
\end{abstract}

Keywords: UCP2, polymorphisms, diabetic kidney disease.

Received: Dezembro 11, 2018; Accepted: April 11, 2019.

\section{Introduction}

Diabetic kidney disease (DKD) is a common microvascular complication that affects $40 \%$ of patients with diabetes mellitus (DM) (Gross et al., 2005, Macisaac et al., 2014). DKD is the leading cause of end-stage renal disease in subjects starting renal replacement therapy and is associated with increased cardiovascular mortality (Gross et al., 2005, Assmann et al., 2018). This complication is a progressive disease, characterized by pathophysiological changes resulting from the diabetic milieu, which begin with glomerular hypertrophy and hyperfiltration, and might progress to albuminuria and a gradual decline in the glomerular filtration rate (GFR) (Kanwar et al., 2011, Ritz et al., 2011). The progressive decline in renal function during DKD is a result of pathophysiological alterations in the kidneys, such as mesangial expansion and tubulointerstitial fibrosis due to the accumulation of extracellular matrix proteins, basement

Send correspondence to Daisy Crispim. Hospital de Clínicas de Porto Alegre, Endocrine Division, Porto Alegre, RS, Brazil. E-mail: dcmoreira@hcpa.edu.br. membrane thickening, and podocyte dysfunction (Assmann et al., 2018) (Figure 1). The main risk factors for DKD are the duration of chronic hyperglycemia, arterial hypertension, dyslipidemia, and genetic susceptibility (Carpena et al., 2010, Ahlqvist et al., 2015).

At the cellular level, chronic hyperglycemia causes renal damage through five main mechanisms: increased formation of advanced glycation end-products; increased expression of the receptor for advanced glycation end-products; activation of protein kinase $\mathrm{C}$ isoforms; increased flux of glucose through the polyol pathway; and upregulation of the hexosamine pathway ( $\mathrm{Du}$ et al., 2000, Giacco and Brownlee, 2010). Several lines of evidence have shown that the mitochondrial overproduction of reactive oxygen species (ROS) is the unifying upstream mechanism by which hyperglycemia activates all these five pathways (Brownlee, 2005; Rich, 2006; Giacco and Brownlee, 2010).

Uncoupling protein 2 (UCP2) is a mitochondrial anion carrier protein expressed in a number of tissues, including adipose tissue, liver, kidney, and retina (Souza et al., 2011; Donadelli et al., 2014). This protein mildly uncouples the 


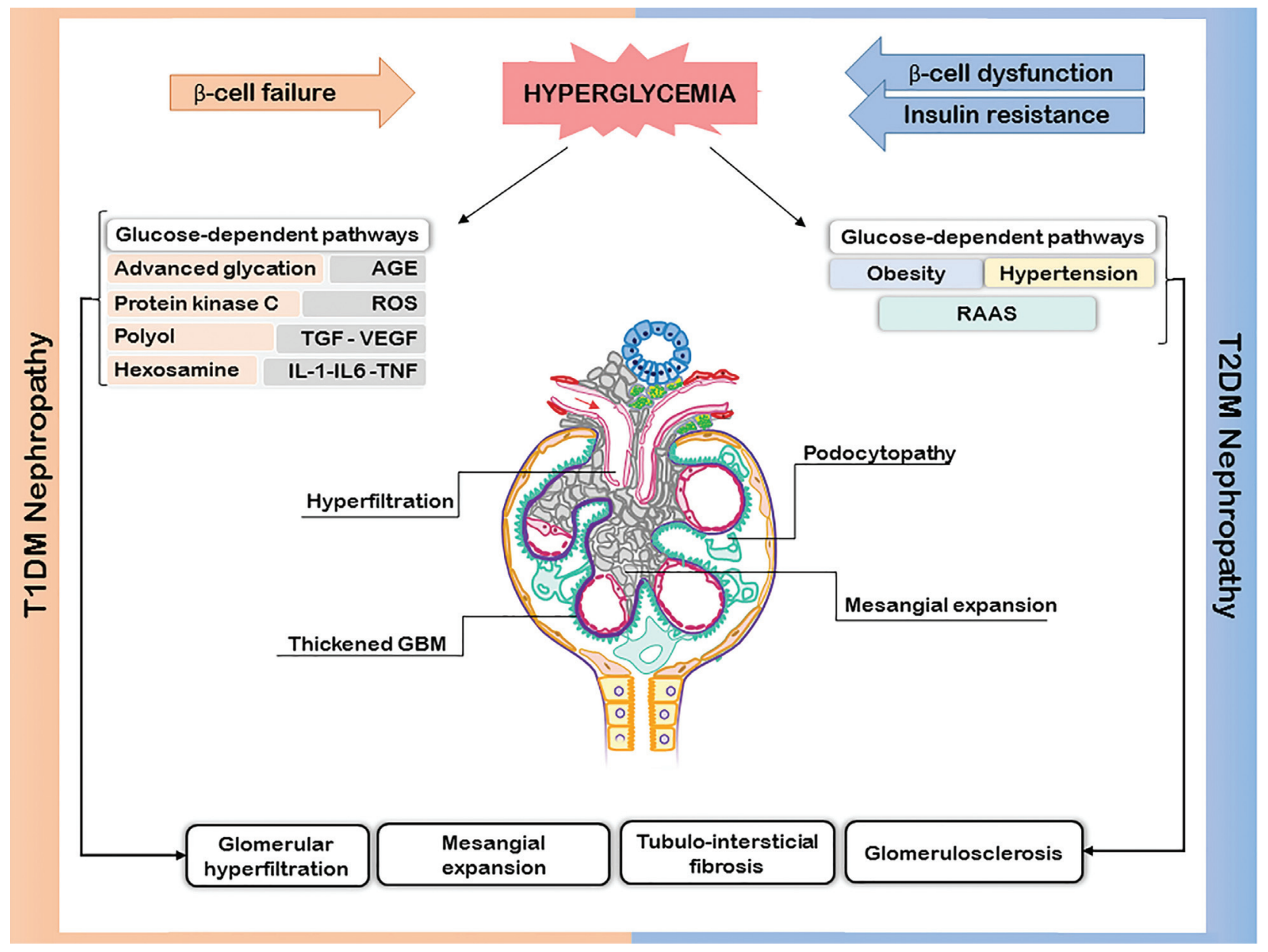

Figure 1 - DKD pathogenesis in T1DM and T2DM. Chronic hyperglycemia has a central role in the pathophysiology of DKD. In T1DM, chronic hyperglycemia activates several known pathways associated with the development and progression of the diabetic nephropathy, to cite: advanced glycation, polyol, hexosamine and protein kinase C pathways. In T2DM, besides these pathways, the presence of obesity and/or hypertension through hemodynamic mechanisms activates the renin-angiotensin-aldosterose system (RAAS), leading to glomerular hyperfiltration. All these factors participate in the pathophysiology of the DKD, characterized by the thickness of the glomerular basement membrane (GBM), podocytopathy, mesangial expansion and glomerulosclerosis, and that are the key mechanisms to diabetic nephropathy. AGE: advanced glycation end-products; ROS: reactive oxygen species; TGF: transforming growth factor; VEGF: vascular endothelial growth factor; IL: interleukin; TNF: tumor necrosis factor.

oxidative phosphorylation from ATP synthesis by dissipating the proton gradient generated across the mitochondrial inner membrane; thereby, decreasing ATP production. The uncoupling then leads to tissue-specific functions, such as regulation of glucose and lipid metabolism and immune cell activation and, importantly, reducing ROS formation by mitochondria (Souza et al., 2011; Toda and Diano, 2014).

Consistent with the role of UCP2 in decreasing oxidative stress, several studies have suggested that polymorphisms in the UCP2 gene are associated with ROS-related pathologies (Ji et al., 2004; Yu et al., 2009; Chai et al., 2012) and with the development of DM and its chronic complications (Jia et al., 2009; Crispim et al., 2010; de Souza et al., 2012, 2013, 2015). To date, three common UCP2 polymorphisms have been well studied: the functional -866G/A polymorphism (rs659366) in the promoter region; the Ala55Val polymorphism (rs660339) in exon 4, and the $45 \mathrm{bp}$ insertion/deletion (Ins/Del) polymorphism in the 3' untranslated region (Jia et al., 2009; Dalgaard, 2011).
Our group previously showed that the polymorphic UCP2 $-866 \mathrm{~A} / 55 \mathrm{Val} / \mathrm{Ins}$ haplotype (constituted by the -866G/A, Ala55Val, and Ins/Del polymorphisms) was associated with risk for proliferative diabetic retinopathy (DR) in type 1 and type 2 diabetic patients (Crispim et al., 2010). The $-866 \mathrm{G} / \mathrm{A}$ and the Ala55Val polymorphisms were in almost complete linkage disequilibrium in our population from the South of Brazil (Crispim et al., 2010). Recently, we reported that the polymorphic $-866 \mathrm{~A} / 55 \mathrm{Val} / \mathrm{Ins}$ haplotype was also an independent risk factor for $\mathrm{DKD}(\mathrm{OR}=2.14,95 \% \mathrm{CI} 1.04$ -4.40 ) in patients with type 2 diabetes mellitus (T2DM) (de Souza et al., 2015). Moreover, T2DM patients carrying the polymorphic haplotype showed lower estimated GFR compared with patients carrying the reference haplotype (-866G/Ala55/Del). Interestingly, the polymorphic haplotype was associated with decreased UCP2 gene expression in human kidney biopsy samples (de Souza et al., 2015).

Therefore, here we performed a case-control study to investigate if the UCP2 -866G/A and Ins/Del polymor- 
phisms were also associated with DKD in patients with type 1 diabetes mellitus (T1DM). Additionally, we conducted a systematic review and meta-analysis of the literature on the subject as part of the ongoing effort to evaluate if UCP2 polymorphisms are associated with DKD in T1DM or T2DM patients.

\section{Subjects and Methods}

\section{Case-control study}

\section{Subjects, phenotype measurements, and laboratory} analyses

This case-control study was designed in agreement with STROBE and STREGA guidelines for reporting of genetic association studies (von Elm et al., 2008; Little et al., 2009). The sample population comprised 162 T1DM patients with DKD (cases) and 223 T1DM patients without this complication and with at least 10 years of DM duration (T1DM controls). All T1DM patients were recruited from the outpatient clinic at Hospital de Clínicas de Porto Alegre (Rio Grande do Sul, Brazil). Patients were diagnosed as having T1DM according to American Diabetes Association guidelines (American Diabetes Association, 2018). A standard questionnaire was used to collect information on age, age at T1DM diagnosis, T1DM duration, and drug treatment. In addition, all patients underwent physical and laboratory evaluations, as previously described (Boucas et al., 2013; Assmann et al., 2014). The ethnic group was defined based on self-classification.

Serum and plasma samples were taken after $12 \mathrm{~h}$ of fasting for laboratory analyses (Boucas et al., 2013; Assmann et al., 2014). Glucose levels were determined using the glucose oxidase method. Glycated hemoglobin (HbA1c) levels were measured by different methods and the results were traceable to the Diabetes Control and Complications Trial method by off-line calibration or using a conversion formulae (Camargo et al., 1998). Creatinine was measured by the Jaffé reaction; total plasma cholesterol, HDL cholesterol and triglycerides by enzymatic methods, and albuminuria by immunoturbidimetry (Sera-Pak immuno microalbuminuria, Bayer, Tarrytown, NY, USA) (Zelmanovitz et al., 1997).

The diagnosis of DKD was based on the urinary albumin excretion (UAE) in at least two out of three consecutive $24 \mathrm{~h}$ timed urine samples in a 6-month period. Patients were classified as having normal to mildly increased UAE (UAE $<30 \mathrm{mg} / 24 \mathrm{~h}$, control group), moderately increased UAE (UAE $30-299 \mathrm{mg} / 24 \mathrm{~h}$ ) or severely increased UAE (UAE $>300 \mathrm{mg} / 24 \mathrm{~h}$ ) (KDIGO Group, 2013). Therefore, the case group comprised patients who had moderately to severely increased UAE (moderate to severe DKD). Patients with other causes of albuminuria or renal diseases were excluded from the study. The estimated GFR was calculated using the Chronic Kidney Disease Epidemiology Collaboration (CKD-EPI) equation: estimated GFR $=141 \mathrm{x} \min (\mathrm{SCR} / \kappa$, $1)^{\alpha} \times \max (\mathrm{SCR} / \kappa, 1)^{-1,209} \times 0,993^{\text {age }} \times 1,018$ [if female] $\mathrm{x}$ 1,159 [if black] (Levey et al., 2009).
In addition, we also included a third group constituted of 489 healthy blood donors recruited from the same hospital, and who did not have diabetes or family history of this disease. These subjects were used as non-diabetic controls; thus, only subjects with $\mathrm{HbA} 1 \mathrm{c}<5.7 \%$ were included in this group (American Diabetes Association, 2018). All subjects gave assent and written informed consent prior to participation. The study protocol was approved by Ethic Committee in Research from Hospital de Clínicas de Porto Alegre.

\section{Genotyping}

DNA was extracted from peripheral blood leucocytes by a standardized salting-out procedure (Lahiri and Nurnberger, 1991). UCP2 -866G/A polymorphism (rs659366) was genotyped using primers and probes contained in the TaqMan SNP Genotyping Assay 20 (Thermo Fisher Scientific, Foster City, CA, USA - assay ID: C 8760350 10). Real-Time PCR reactions were performed in 384 well plates, in a total $5 \mu \mathrm{L}$ volume, using 2 ng of DNA, TaqMan Genotyping Master Mix 1 (Thermo Fisher Scientific) and TaqMan Genotyping Assay 1. The assays were done in a real-time PCR thermal cycler (ViiA7 Real-Time PCR System; Thermo Fisher Scientific) with the following protocol: heating for $10 \mathrm{~min}$ at $95^{\circ} \mathrm{C}$, followed by 50 cycles of $95^{\circ} \mathrm{C}$ for $15 \mathrm{~s}$ and $62^{\circ} \mathrm{C}$ for $90 \mathrm{~s}$. Genotyping of the UCP2 $45 \mathrm{bp}$ Ins/Del polymorphism was performed by direct separation of the PCR products on $2.5 \%$ agarose gel stained with GelRed, as previously described (de Souza et al., 2012).

As the $-866 \mathrm{G} / \mathrm{A}$ polymorphism is in almost complete linkage disequilibrium with the Ala55Val polymorphism $\left(\left|\mathrm{D}^{\prime}\right|=0.991, \mathrm{r}^{2}=0.905\right)$ in our population, only the UCP2 $-866 \mathrm{G} / \mathrm{A}$ and Ins/Del polymorphisms were analyzed in the present case-control study (Crispim et al., 2010).

\section{Statistical analyses for the case-control study}

Allele frequencies were determined by gene counting, and departures from the Hardy-Weinberg Equilibrium were verified using the $\chi^{2}$ test. Allele and genotype frequencies were compared between groups of subjects using $\chi^{2}$ tests. Between all pairs of biallelic loci, we examined widely used measures of linkage disequilibrium, Lewontin's D' |D'| and $r^{2}$ (Hedrick, 1987). Haplotypes constructed with the combination of the two UCP2 polymorphisms and their frequencies were inferred using the PHASE 2.1 program, which implements a Bayesian statistical method (Stephens et al., 2001).

Clinical and laboratory characteristics were compared between group of patients categorized according to the different genotypes of the two UCP2 polymorphisms using unpaired Student's $t$ test, One-Way ANOVA or $\chi^{2}$ test, as appropriate. Variables with normal distribution are shown as mean \pm SD or percentage. Variables with skewed distribution were log-transformed before analysis and are shown as median $\left(25^{\text {th }}-75^{\text {th }}\right.$ percentile values $)$. Multivariate logistic regression analyses were done to evaluate the independent association of each individual UCP2 polymorphism or haplotypes with DKD, adjusting for possible confounding fac- 
tors. Variables with significant associations with DKD in the univariate analysis, or with an important biological association with this complication were chosen for inclusion in the multivariate model. T1DM duration was not included as an independent variable in these analyses since T1DM control group was selected based on this characteristic. Statistical analyses were performed using the SPSS 18.0 software (SPSS, Chicago, IL), and $P$-values $<0.05$ were considered significant.

\section{Systematic review and meta-analysis}

\section{Search strategy and eligibility criteria}

This study was designed and reported in accordance with the Preferred Reporting Items for Systematic Reviews and Meta-Analyses (PRISMA) and Meta-analysis of Observational Studies in Epidemiology (MOOSE) statements (Stroup et al., 2000; Moher et al., 2009). PubMed and Embase repositories were searched to retrieve all articles that investigated associations between DKD and at least one of the two polymorphisms of interest. The Medical Subject Headings used for this search are shown in Supplementary Material - MeSH terms. The search was restricted to human studies and English, Portuguese, or Spanish language articles, and was completed on December, 2018. References from all articles identified were searched manually to find other relevant studies.

Eligibility evaluation was made by title and abstracts review, and when abstracts did not provide adequate information, the full text of the paper was retrieved for evaluation. This was done independently in a standardized manner by two investigators (C.D. and N.E.L.), as previously described (de Souza et al., 2013; Brondani et al., 2014). Discrepancies were solved by discussion between them and, when necessary, a third reviewer (D.C.) was accessed. Observational studies that compared the $-866 \mathrm{G} / \mathrm{A}$ or Ins/Del polymorphisms between patients with and without DKD were included in the meta-analysis. Articles were excluded from the analysis if genotype frequencies in the control group deviated from those predicted by the Hardy-Weinberg Equilibrium, or if they did not have enough data to estimate an OR with $95 \%$ CI. If results were duplicated and had been published more than once, the most complete study was chosen.

\section{Data extraction and quality control assessment}

Necessary information from each study was independently extracted by two investigators (C.D. and N.E.L.) using a standardized extraction form (de Souza et al., 2013; Brondani et al., 2014), and consensus was sought in all extracted items. When consensus could not be achieved, differences in data extraction were decided by reading the original publication or by consulting a third reviewer (D.C.). Data extracted from each study was as follows: (1) characteristics of each study and its samples (including name of the first author, publication year, number of subjects in case and control groups, mean age, gender, ethnicity, and age at T1DM or T2DM diagnosis); (2) case and control definitions; (3) poly- morphism frequencies and OR $(95 \% \mathrm{CI})$. When data were not available, the authors were contacted by e-mail.

Two investigators (C.D. and N.E.L.) independently evaluated the quality of each selected study using the Newcastle-Ottawa Scale (NOS) (Stang, 2010). The NOS contains eight items divided into three dimensions: selection, comparability, and exposure. For each item, a sequence of answer options is provided. A star scoring system is used to allow a semi-quantitative evaluation of paper quality, such that the highest quality studies are given a maximum of one star for each item, with exception of the item related to comparability, which allows two stars to be given. Therefore, the final NOS score varies from 0 to 9 stars.

\section{Statistical analysis for meta-analysis}

Genotype distributions in control groups were tested for conformity with the Hardy-Weinberg Equilibrium using a goodness-of-fitness $\chi^{2}$ test. Associations between polymorphisms and DKD were analyzed using OR (95\% CI) calculations based on allele contrast, dominant, recessive and additive inheritance models (Minelli et al., 2005). Heterogeneity was tested using $\chi^{2}$-based Cochran's Q statistic and inconsistency was assessed with the $\mathrm{I}^{2}$ metric (Higgins and Thompson, 2002; Higgins et al., 2003). Heterogeneity was considered statistically significant at $P<0.10$ for the Q statistic and/or $\mathrm{I}^{2}>50 \%$ for the $\mathrm{I}^{2}$ statistic. Where significant heterogeneity was detected, the DerSimonian and Laird random effect model (REM) was used to calculate OR (95\% CI) for each study and for the pooled effect; where heterogeneity was not significant, the fixed effect model was used. Sensitivity analyses were performed to recognize important studies with a considerable impact on inter-study heterogeneity. All statistical analyses were performed using Stata 11.0 software (StataCorp, College Station, TX, USA).

\section{Results}

\section{Case-control study}

Comparisons of clinical and laboratorial characteristics between T1DM case and control groups, categorized according to UAE values, are show in Table 1. As expected, HbA1c, triglycerides, total cholesterol, LDL cholesterol, and creatinine levels were increased in patients with DKD compared to T1DM controls. Prevalence of arterial hypertension and DR were also increased in the DKD group. Estimated GFR was decreased in patients with DKD compared to T1DM controls. The ethnic proportion did not differ significantly between case and control groups: $10.5 \%$ of black subjects in the case group vs. 5.4\% of black subjects in the control group $(P=0.093)$. Frequencies of the minor alleles of the $-866 \mathrm{G} / \mathrm{A}$ and Ins/Del polymorphisms in white and black subjects were: $40.5 \%$ vs. $44.8 \%$ for the -866 A allele $(P$ $=0.814)$, and $30.7 \%$ vs. $20.3 \%$ for the Ins allele $(P=0.386)$.

Table 2 shows genotype and allele frequencies of the -866G/A and Ins/Del polymorphisms in T1DM patients with UAE $>30 \mathrm{mg} / 24 \mathrm{~h}$ (DKD cases) and T1DM patients with UAE $<30 \mathrm{mg} / 24 \mathrm{~h}$ (T1DM controls). Genotype distribu- 
Table 1 - Clinical and laboratory characteristics of T1DM patients with UAE $>30 \mathrm{mg} / 24 \mathrm{~h}$ (DKD cases) and T1DM patients with UAE $<30$ $\mathrm{mg} / 24 \mathrm{~h}$ (T1DM controls).

\begin{tabular}{|c|c|c|c|}
\hline Characteristics & $\begin{array}{c}\text { T1DM } \\
\text { controls } \\
(\mathrm{n}=223)\end{array}$ & $\begin{array}{l}\text { DKD cases } \\
(\mathrm{n}=162)\end{array}$ & $P^{*}$ \\
\hline Age (years) & $36.8 \pm 12.8$ & $37.7 \pm 13.6$ & 0.478 \\
\hline Gender ( $\%$ male $)$ & 47.5 & 48.8 & 0.892 \\
\hline Ethnicity (\% black) & 5.4 & 10.5 & 0.093 \\
\hline HbA1c $(\%)$ & $8.4 \pm 1.7$ & $9.5 \pm 2.2$ & 0.0001 \\
\hline $\operatorname{BMI}\left(\mathrm{kg} / \mathrm{m}^{2}\right)$ & $24.2 \pm 3.6$ & $23.9 \pm 3.6$ & 0.413 \\
\hline Hypertension (\%) & 31.8 & 46.0 & 0.012 \\
\hline Age at diagnosis (years) & $15.4 \pm 10.0$ & $15.4 \pm 10.6$ & 0.993 \\
\hline T1DM duration (years) & $20.7 \pm 8.2$ & $20.6 \pm 10.5$ & 0.956 \\
\hline Systolic BP (mmHg) & $121.1 \pm 15.7$ & $123.4 \pm 19.3$ & 0.244 \\
\hline Diastolic BP (mmHg) & $77.2 \pm 10.6$ & $78.3 \pm 13.5$ & 0.423 \\
\hline Triglycerides (mg/dL) & $\begin{array}{c}70.0 \\
(51.7-98.5)\end{array}$ & $\begin{array}{c}100.0 \\
(70.2-159.5)\end{array}$ & $<0.001$ \\
\hline Total cholesterol (mg/dL) & $177.7 \pm 42.1$ & $193.0 \pm 58.0$ & 0.007 \\
\hline LDL cholesterol (mg/dL) & $100.8 \pm 30.6$ & $111.5 \pm 48.0$ & 0.031 \\
\hline HDL cholesterol (mg/dL) & $57.7 \pm 16.7$ & $56.2 \pm 19.0$ & 0.429 \\
\hline Diabetic retinopathy (\%) & 44.8 & 66.9 & $<0.001$ \\
\hline Serum creatinine $(\mu \mathrm{g} / \mathrm{dL})$ & $\begin{array}{c}0.9 \\
(0.7-1.0)\end{array}$ & $\begin{array}{c}1.0 \\
(0.8-1.6)\end{array}$ & $<0.001$ \\
\hline eGFR $\left(\mathrm{ml} / \mathrm{min} / 1.73 \mathrm{~m}^{2}\right)$ & $\begin{array}{c}104.0 \\
(87.2-121.0)\end{array}$ & $\begin{array}{c}87.0 \\
(46.0-117.0)\end{array}$ & $<0.001$ \\
\hline $\mathrm{UAE}(\mathrm{mg} / \mathrm{g})$ & $\begin{array}{c}5.5 \\
(3.3-10.7)\end{array}$ & $\begin{array}{c}86.9 \\
(39.0-353.8)\end{array}$ & - \\
\hline
\end{tabular}

Data are shown by mean \pm standard deviation, median $\left(25^{\text {th }}-75^{\text {th }}\right.$ percentile values) or \%. BMI: body mass index; BP: blood pressure; DKD: diabetic kidney disease; eGFR: estimated glomerular filtration rate; HbA1c: glycated hemoglobin; T1DM: type 1 diabetes mellitus; UAE: urinary albumin excretion. ${ }^{*} P$-values were calculated using Student's $t$-tests, or Chi-square tests, as appropriate.

tions of the two analyzed polymorphisms were in agreement with those predicted by the Hardy-Weinberg Equilibrium in both groups $(P \geq 0.05)$, and they were similar between DKD cases and T1DM controls (Table 2). Of note, this result did not change after adjustment for ethnicity, HbAlc, serum creatinine, and triglycerides (Table 2). Accordingly, allele distributions of the $-866 \mathrm{G} / \mathrm{A}$ and Ins/Del polymorphisms did not differ between case and control groups, and these polymorphisms were also not associated with DKD when assuming different genetic inheritance models (Table 2). It is worth of note that when we stratified patients according to the UAE severity (T1DM controls vs. patients with moderate UAE $v s$. severe UAE), -866G/A and Ins/Del frequencies also did not differ significantly among groups (Table S1).

The $-866 \mathrm{G} / \mathrm{A}$ polymorphism is in moderate linkage disequilibrium with the Ins/Del polymorphism $\left(\left|\mathrm{D}^{\prime}\right|=0.711\right.$, $\left.r^{2}=0.311\right)$ in our population. Four haplotypes $(\mathrm{Ht})$ produced by the combination of these two polymorphisms were inferred in the total sample of T1DM patients: $-866 \mathrm{G} / \mathrm{Del}$ (Ht1; 52.7\%), -866A/Del (Ht2; 17.2\%), -866G/Ins (Ht3; $6.5 \%$ ) and $-866 \mathrm{~A} / \mathrm{Ins}(\mathrm{Ht} 4 ; 23.6 \%)$. Distributions of these haplotypes were similar between T1DM controls and cases with DKD $(P=0.892)$ (Table 3$)$. Moreover, frequency of 3 or 4 minor alleles of the $-866 \mathrm{G} / \mathrm{A}$ and Ins/Del polymorphisms (Ht3/Ht4 or Ht4/Ht4) were similar between T1DM controls and patients with DKD (17.2\% vs. $15.3 \%$, adjusted $P=0.604$; Table 2). These frequencies were also similar among groups according to the severity of DKD (T1DM controls $v s$. moderate UAE $v s$. severe UAE; $P=0.805$; Table S1).

In an exploratory analysis, all clinical and laboratory characteristics showed in Table 1 were then compared between all T1DM patients (control + case subjects) broken down by the presence of the $-866 \mathrm{G} / \mathrm{A}$ and Ins/Del polymorphisms. The frequency of DR was not significantly different among -866G/A genotypes (G/G: 49.2\%; G/A: 53.8\% and $\mathrm{A} / \mathrm{A}: 65.1 \% ; P=0.117)$. In contrast, presence of DR was increased in patients carrying the Ins/Ins genotype (81.8\%) compared to patients with the Del/Del or Ins/Del genotypes (48.5\% and $57.0 \%$, respectively; $P=0.002$ ). Frequency of DR was $70.4 \%$ in patients carrying 3 or 4 minor alleles of the $-866 \mathrm{G} / \mathrm{A}$ and Ins/Del polymorphisms, $49.7 \%$ in patients with $0 / 1$ minor allele, and $54.1 \%$ in patients with 2 minor alleles $(P=0.029)$. No other characteristic described in Table 1 differed among the genotypes of the two analyzed polymorphism (data not shown). Genotype and allele frequencies of the $-866 \mathrm{G} / \mathrm{A}$ and Ins/Del polymorphisms were similar between T1DM patients (T1DM controls + DKD patients) and non-diabetic subjects (Table S2), suggesting that these two polymorphisms are not associated with T1DM risk.

\section{Systematic review and meta-analysis}

Figure 2 shows a flow diagram illustrating the strategy used to identify and select articles for inclusion in our metaanalysis. A total of 182 possible relevant citations were retrieved from PubMed and Embase, and 178 of them were excluded during the review of titles and abstracts. Four articles remained to be fully evaluated. Nevertheless, following careful analysis of their full texts, one article was excluded because it did not have a control group. Therefore, three articles (Lindholm et al., 2004; Tiwari et al., 2009; de Souza et al., 2015) plus the present case-control study were included in our meta-analysis, totalizing four articles (five studies). In total, 717 controls without DKD and 648 cases with this complication were analyzed for the $-866 \mathrm{G} / \mathrm{A}$ polymorphism, and 937 controls and 857 cases for the Ins/Del polymorphism. The article by Tiwari et al. (2009) analyzed the two $U C P 2$ polymorphisms in two different populations from South India and North India, and, because of that, their results are shown separately.

With exception of the present case-control study, the other three articles included only T2DM patients. Two studies comprised Caucasian populations (Lindholm et al., 2004; de Souza et al., 2015), the present study investigated a mixed population, while Tiwari et al. (2009) analyzed two Asian populations. All studies investigated the Ins/Del polymorphism, while the study by Lindholm et al. (2004) was the only one that did not investigate the $-866 \mathrm{G} / \mathrm{A}$ polymor- 
Table 2 - Genotype and allele frequencies of UCP2 -866G/A and Ins/Del polymorphisms in T1DM patients with UAE $>30 \mathrm{mg} / 24 \mathrm{~h}$ (DKD cases) and in T1DM patients with $\mathrm{UAE}<30 \mathrm{mg} / 24 \mathrm{~h}$ (T1DM controls).

\begin{tabular}{|c|c|c|c|c|}
\hline Polymorphisms & T1DM controls & DKD cases & $\begin{array}{c}\text { OR (95\% CI)/ Unadjusted } P \text { - } \\
\text { value* }\end{array}$ & $\begin{array}{c}\text { Adjusted OR }(95 \% \mathrm{CI}) / \uparrow P \text { - } \\
\text { value }\end{array}$ \\
\hline$-866 G / A$ & $\mathrm{n}=223$ & $\mathrm{n}=162$ & & \\
\hline \multicolumn{5}{|l|}{ Genotype } \\
\hline $\mathrm{G} / \mathrm{G}$ & $77(34.5)$ & $61(37.7)$ & 1 & 1 \\
\hline $\mathrm{G} / \mathrm{A}$ & $107(48.0)$ & $72(44.4)$ & $0.849(0.542-1.332) / 0.477$ & $0.779(0.447-1.359) / 0.379$ \\
\hline $\mathrm{A} / \mathrm{A}$ & $39(17.5)$ & $29(17.9)$ & $0.939(0.522-1.687) / 0.832$ & $1.263(0.628-2.541) / 0.513$ \\
\hline \multicolumn{5}{|l|}{ Allele } \\
\hline G & 0.59 & 0.60 & 0.706 & - \\
\hline A & 0.41 & 0.40 & & \\
\hline \multicolumn{5}{|l|}{ Recessive model } \\
\hline $\mathrm{G} / \mathrm{G}+\mathrm{G} / \mathrm{A}$ & $184(82.5)$ & $133(82.1)$ & 1 & 1 \\
\hline $\mathrm{A} / \mathrm{A}$ & $39(17.5)$ & $29(17.9)$ & $1.029(0.606-1.747) / 0.917$ & $1.449(0.771-2.723) / 0.249$ \\
\hline \multicolumn{5}{|l|}{ Additive model } \\
\hline $\mathrm{G} / \mathrm{G}$ & $77(66.4)$ & $61(67.8)$ & 1 & 1 \\
\hline $\mathrm{A} / \mathrm{A}$ & $39(33.6)$ & $29(32.2)$ & $0.939(0.522-1.687) / 0.832$ & $1.313(0.634-2.717) / 0.463$ \\
\hline \multicolumn{5}{|l|}{ Dominant model } \\
\hline $\mathrm{G} / \mathrm{G}$ & $77(34.5)$ & $61(37.7)$ & 1 & 1 \\
\hline $\mathrm{G} / \mathrm{A}+\mathrm{A} / \mathrm{A}$ & $146(65.5)$ & $101(62.3)$ & $0.873(0.573-1.330) / 0.528$ & $0.900(0.538-1.506) / 0.689$ \\
\hline Ins/Del & $\mathrm{n}=222$ & $\mathrm{n}=156$ & & \\
\hline \multicolumn{5}{|l|}{ Genotype } \\
\hline Del/Del & $107(48.2)$ & $82(52.6)$ & 1 & 1 \\
\hline Ins/Del & $93(41.9)$ & $59(37.8)$ & $0.828(0.536-1.279) / 0.394$ & $0.710(0.411-1.225) / 0.219$ \\
\hline Ins/Ins & $22(9.9)$ & $15(9.6)$ & $0.890(0.435-1.822) / 0.749$ & $1.453(0.616-3.551) / 0.393$ \\
\hline \multicolumn{5}{|l|}{ Allele } \\
\hline Del & 0.69 & 0.71 & 0.492 & - \\
\hline Ins & 0.31 & 0.29 & & \\
\hline \multicolumn{5}{|l|}{ Recessive model } \\
\hline Ins/Del + Del/Del & $200(90.1)$ & $141(90.4)$ & 1 & 1 \\
\hline Ins/Ins & $22(9.9)$ & $15(9.6)$ & $0.967(0.485-1.930) / 0.924$ & $1.705(0.749-3.881) / 0.204$ \\
\hline \multicolumn{5}{|l|}{ Additive model } \\
\hline Del/Del & $107(82.9)$ & $82(84.5)$ & 1 & 1 \\
\hline Ins/Ins & $22(17.1)$ & $15(15.5)$ & $0.890(0.435-1.822) / 0.749$ & $1.276(0.545-2.990) / 0.574$ \\
\hline \multicolumn{5}{|l|}{ Dominant model } \\
\hline Del/Del & $107(48.2)$ & $82(52.6)$ & 1 & 1 \\
\hline Ins/Del + Ins/Ins & $115(51.8)$ & $74(47.4)$ & $0.840(0.557-1.265) / 0.403$ & $0.821(0.493-1.367) / 0.448$ \\
\hline $\begin{array}{l}\text { Presence of the } U C P 2 \mathrm{mu}- \\
\text { tated haplotype }\end{array}$ & $(\mathrm{n}=209)$ & $(\mathrm{n}=150)$ & & \\
\hline 0 or 1 mutated allele & $110(52.6)$ & $83(55.3)$ & 1 & 1 \\
\hline 2 mutated alleles & $63(30.2)$ & $44(29.4)$ & $0.926(0.573-1.494) / 0.752$ & $0.751(0.411-1.372) / 0.352$ \\
\hline 3 or 4 mutated alleles & $36(17.2)$ & $23(15.3)$ & $0.847(0.467-1.536) / 0.584$ & $1.207(0.593-2.458) / 0.604$ \\
\hline
\end{tabular}

Data are shown as number (\%) or proportion. DKD: diabetic kidney disease; T1DM: type 1 diabetes mellitus; UAE: urinary albumin excretion. $* P$-values were calculated using Chi-square tests. $\uparrow P$-values and $\mathrm{OR}(95 \% \mathrm{CI})$ obtained using logistic regression analyses adjusting for ethnicity, HbA1c, serum creatinine (logarithmic scale), and triglycerides (logarithmic scale).

phism. Two studies (Lindholm et al., 2004; de Souza et al., 2015) plus the present case-control classified DKD using the UAE, while one study (Tiwari et al., 2009) classified DKD using serum creatinine levels. Genotype and allele distributions of the UCP2 polymorphisms in case and control samples from the different studies, as well as their respective ORs $(95 \% \mathrm{CI})$ for association with DKD, are shown in Table
S3. Quality assessment using the NOS scale showed that most studies were considered as having good quality since 8 stars were given for the studies by Lindholm et al. (2004) and Souza et al. (2015), and 7 stars for the study by Tiwari et al. (2009).

Table 4 summarizes the results of quantitative pooled analyses for associations between $-866 \mathrm{G} / \mathrm{A}$ and $\mathrm{Ins} / \mathrm{Del}$ 


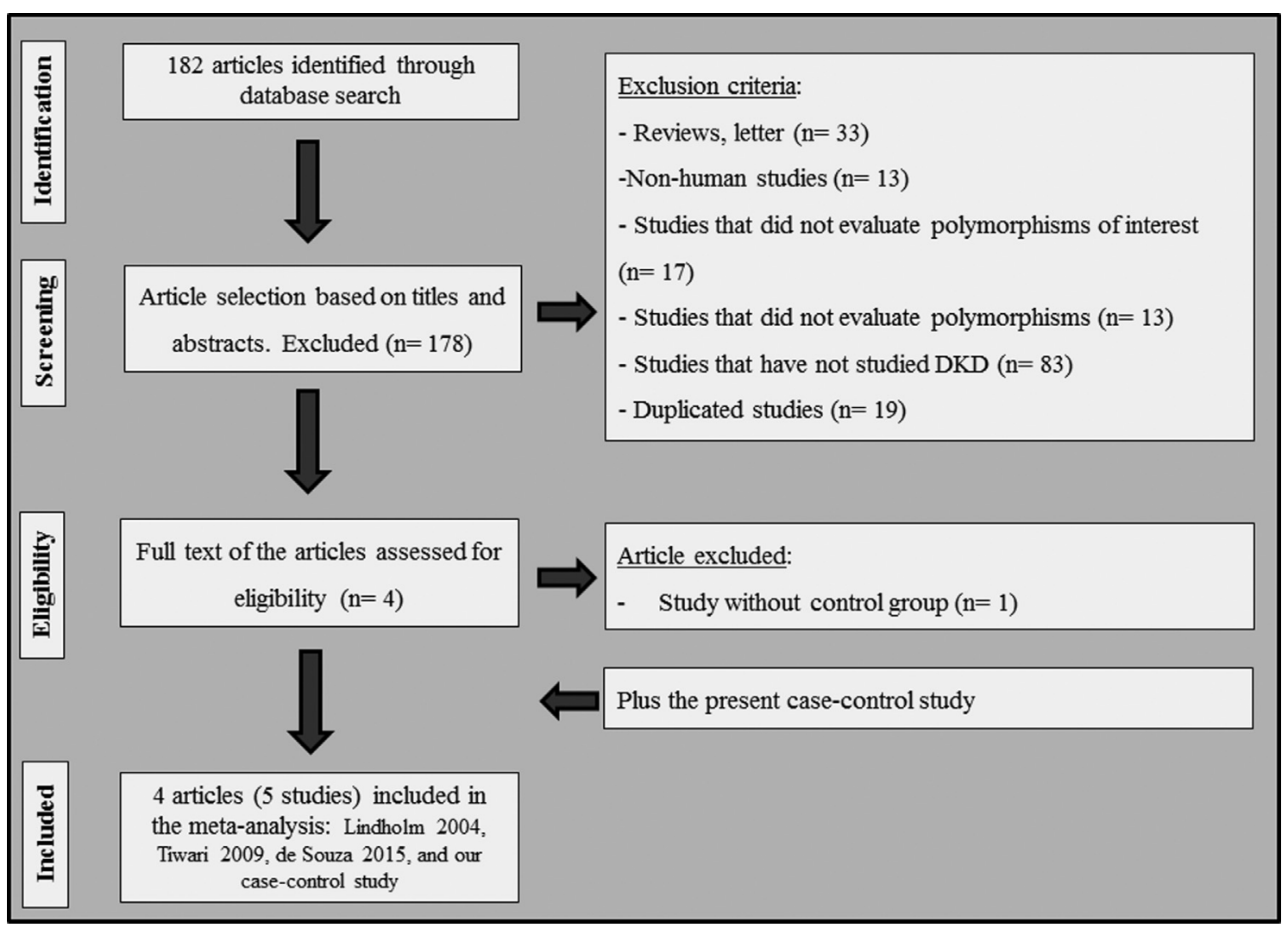

Figure 2 - Flow diagram illustrating the search strategy used to identify association studies of $U C P 2$ polymorphisms and DKD for inclusion in the meta-analysis study.

Table 3 - Haplotypes of the $U C P 2$ polymorphisms in T1DM patients with and without DKD.

\begin{tabular}{lccc}
\hline Haplotypes & $\begin{array}{c}\text { T1DM con- } \\
\text { trols }(\mathrm{n}=418)\end{array}$ & $\begin{array}{c}\text { DKD cases } \\
(\mathrm{n}=300)\end{array}$ & $P$-value \\
\hline Ht 1 (-866G/Del) & 0.518 & 0.540 & \\
Ht 2 (-866A/Del) & 0.171 & 0.173 & 0.892 \\
Ht 3 (-866G/Ins) & 0.069 & 0.060 & \\
Ht 4 (-866A/Ins) & 0.242 & 0.227 & \\
\hline
\end{tabular}

Data are presented as proportion. $\mathrm{n}=$ number of chromosomes. DKD: diabetic kidney disease; T1DM: type 1 diabetes mellitus. The first letter of the haplotypes refers to the $-866 \mathrm{G} / \mathrm{A}$ polymorphism and the second to the Ins/Del polymorphism. $P$-values for the comparisons of haplotype frequencies between patients with or with DKD were calculated using permutations tests.

polymorphisms and susceptibility to DKD. Our results showed no significant associations between these polymorphisms and DKD under allele contrast, additive, recessive, or dominant inheritance models. A significant heterogeneity was observed among studies of the $-866 \mathrm{G} / \mathrm{A}$ polymorphism considering the dominant model of inheritance (Table 4). Thus, sensitivity analyses were performed to evaluate the effect of each individual study on the meta-analysis performed for this model. This was carried out by repeating the metaanalysis excluding a different study at a time. These analyses showed that the study by Tiwari et al. (2009) explained the observed heterogeneity in the meta-analysis of the $-866 \mathrm{G} / \mathrm{A}$ polymorphism under a dominant model. However, after exclusion of this study from the respective meta-analysis, the pooled OR did not remain significant $(\mathrm{OR}=0.91,95 \% \mathrm{CI}$ $0.71-1.16)$.

\section{Discussion}

ROS overproduction is one of the main mechanisms by which hyperglycemia leads to chronic diabetic complications, including DKD (Brownlee, 2005; Rich, 2006; Giacco and Brownlee, 2010). Although UCP2 has a recognized role in reducing oxidative stress, to date, only few studies have evaluated the association between polymorphisms in the $U C P 2$ gene and DKD. Therefore, aiming to better understand the relationship between the UCP2 $-866 \mathrm{G} / \mathrm{A}$ and Ins/Del polymorphisms and the development of this chronic diabetic complication, we performed a case-control study and a meta-analysis of genetic association studies on this subject.

It is well known that functional polymorphisms might influence gene expression and regulate the final quantity of the corresponding protein in a given tissue. Among the three common polymorphisms more studied in the UCP2 gene, only the $-866 \mathrm{G} / \mathrm{A}$ polymorphism is clearly functional. This polymorphism is located in the $U C P 2$ promoter region and alters an important binding site of transcription factors; therefore, increasing or decreasing $U C P 2$ expression according to the binding of tissue-specific transcription factors 
Table 4 - Pooled measures for associations between the UCP2 -866G/A and Ins/Del polymorphisms and susceptibility to DKD.

\begin{tabular}{|c|c|c|c|c|c|}
\hline Inheritance model & $n$ studies & $n$ controls & $n$ cases & $\mathrm{I}^{2}(\%)$ & Pooled OR $(95 \% \mathrm{CI})$ \\
\hline \multicolumn{6}{|l|}{$U C P 2-866 G / A$} \\
\hline Allele contrast ${ }^{\mathrm{b}}$ & 4 & 717 & 648 & 46.0 & $1.03(0.88-1.21)$ \\
\hline Additive $^{\mathrm{b}}$ & 4 & 390 & 351 & 0.0 & $1.04(0.75-1.45)$ \\
\hline Recessive $^{b}$ & 4 & 717 & 648 & 0.0 & $1.05(0.78-1.42)$ \\
\hline Dominant $^{\mathrm{a}}$ & 4 & 717 & 648 & 53.2 & $1.04(0.74-1.45)$ \\
\hline \multicolumn{6}{|l|}{ UCP2 Ins/Del } \\
\hline Allele contrast ${ }^{\mathrm{b}}$ & 4 & 719 & 641 & 0.0 & $0.96(0.81-1.14)$ \\
\hline Additive $^{\mathrm{b}}$ & 4 & 444 & 413 & 0.0 & $1.08(0.71-1.63)$ \\
\hline Recessive $^{b}$ & 4 & 719 & 641 & 13.3 & $1.11(0.74-1.65)$ \\
\hline Dominant $^{\mathrm{b}}$ & 5 & 937 & 857 & 0.0 & $0.89(0.74-1.08)$ \\
\hline
\end{tabular}

${ }^{a}$ If significant heterogeneity was detected $\left(\mathrm{I}^{2}>50 \%\right)$, the DerSimonian and Laird random effect model (REM) was used to calculated OR $(95 \% \mathrm{CI}){ }^{\mathrm{b}}$ if heterogeneity was not significant, the fixed effect model (FEM) was used for this calculation. DKD: diabetic kidney disease.

(Oberkofler et al., 1997; Cassell et al., 1999; Esterbauer et al., 2001; Wang et al., 2004; de Souza et al., 2012). Although there is no evidence that the Ins/Del polymorphism has a functional impact on $U C P 2$ expression, it is located in the 3' untranslated region of the gene. This region is the main site for ligation of microRNAs, which are major regulators of gene expression (Assmann et al., 2018). Thus, the Ins/Del polymorphism might change a ligation site for some microRNAs. Indeed, in a previous study, we used a bioinformatics analysis to show that several predicted interaction regions with microRNAs were found in the UCP2 3' untranslated region. However, only one microRNA (hsa-miR3668) strongly targeted the sequence where the Ins/Del polymorphism is located. The $45 \mathrm{bp}$ Ins allele disrupts the ligation site for this miRNA; thus, probably changing UCP2 expression (de Souza et al., 2015). The Ala55Val polymorphism causes a conservative amino acid change and there is no indication that it causes a functional change in the protein.

Our case-control study suggested that both analyzed polymorphisms and the haplotypes constituted by them are not associated with DKD in T1DM patients. In contrast, our previous study showed that the polymorphic -866A/55Val/Ins haplotype was associated with DKD in Brazilian T2DM patients after adjustment for age, gender, treatment with ACE-inhibitors, triglycerides, and estimated GFR levels (de Souza et al., 2015). In both studies, DKD was classified using UAE levels. Souza et al. (2015) also reported that T2DM patients carrying the $-866 \mathrm{~A} / 55 \mathrm{Val} / \mathrm{Ins}$ haplotype (dominant model) showed lower estimated GFR compared to patients with the reference haplotype, which was not observed in the present study. These discrepancies may be explained by differences in DKD pathophysiology between T1DM and T2DM (Ruggenenti and Remuzzi, 2000). T1DM is caused by autoimmune destruction of pancreatic beta-cells, leading to the total absence of insulin secretion and, consequently, hyperglycemia. As already mentioned, hyperglycemia leads to the activation of glucose-dependent pathways, such as advanced glycation endproducts, protein kinase $\mathrm{C}$, polyol and hexosamine. Excessive activation of these pathways causes the accumulation of their substrates, cellular dysfunction, inflammation, apoptosis, and fibrosis in renal cells exposed to excessive glucose flux (Thomas et al., 2015; Katsarou et al., 2017). In contrast, T2DM is caused by obesity-induced insulin resistance associated with a relative decrease in insulin secretion. Therefore, besides the activation of glucose-dependent pathways, as occurs in T1DM, DKD in T2DM patients is also influenced by obesity, hypertension and dyslipidemia (Thomas et al., 2015) (Figure 1).

Also, we cannot fully exclude the possibility of falsenegative results when analyzing associations between the UCP2 polymorphisms and DKD. Although we had more than an $80 \%$ power $(\alpha=0.05)$ to detect an OR $=2.0$ for the association with the $-866 \mathrm{G} / \mathrm{A}$ and Ins/Del polymorphisms, we cannot rule out the possibility that these polymorphisms would be individually associated with DKD with lower ORs. There is also a possibility that these two polymorphisms are only associated with DR, an association observed in both T1DM and T2DM patients (Crispim et al., 2010). Considering that the majority of DKD patients have some degree of DR (Scheffel et al., 2004), it is plausible that the association with DKD in T2DM patients (de Souza et al., 2015) was not independent of DR.

Meta-analysis has been regarded as a powerful method for pooling data from different studies because it could overcome the problem of small sample sizes, as well as insufficient statistical power of genetic association studies for common diseases (Stroup et al., 2000). Therefore, trying to overcome the problem of small sample size, we also performed a meta-analysis that included three published studies from different populations plus the results from the present case-control study. Meta-analysis results indicated that the $-866 \mathrm{G} / \mathrm{A}$ and Ins/Del polymorphisms are not associated with DKD. Among the studies included in our meta-analysis, only the study by Tiwari et al. (2009) showed an association between the $-866 \mathrm{G} / \mathrm{A}$ polymorphism and DKD in a population from southern India. These authors did not observe an association between this polymorphism and DKD in a population from northern India. The other studies were not able to show an association of the $-866 \mathrm{G} / \mathrm{A}$ or Ins/Del polymor- 
phisms with DKD, including the study by de Souza et al. (2015) that, as already mentioned, only observed an association with the disease when analyzing the haplotypes constituted by the two polymorphisms.

Rudofsky et al. $(2006,2007)$ also observed that the frequency of DKD was similar among German T1DM (Rudofsky et al., 2006) and T2DM (Rudofsky et al., 2006, 2007) patients carrying the different genotypes of the $-866 \mathrm{G} / \mathrm{A}$ polymorphism. These two studies were not included in our meta-analysis because they did not include an appropriate control group. In addition, Tripathi et al. (2008) reported an association between the Ins/Del polymorphism and risk for end-stage renal disease in non-diabetic subjects from northern India; however, genotype distributions of this polymorphism were not in Hardy-Weinberg Equilibrium in the control group. Thus, this study could not be included in our meta-analysis and should be interpreted with caution.

Therefore, to date, most studies indicated that the $-866 \mathrm{G} / \mathrm{A}$ and Ins/Del polymorphisms are not risk factors for DKD. We acknowledge that certain factors unrelated to the $U C P 2$ polymorphisms could have interfered with the present findings. First, meta-analysis is prone to publication bias, and although we have attempted to trace unpublished observations, we cannot be sure that smaller negative studies were overlooked. Second, although the meta-analysis increased the statistical power, the total sample power might still not be sufficient to show associations with lower ORs. Third, heterogeneity is potentially a significant problem when interpreting the results of any meta-analysis, and our metaanalysis showed significant inter-study heterogeneity when analyzing the $-866 \mathrm{G} / \mathrm{A}$ polymorphism in the dominant model of inheritance. The exclusion of the study by Tiwari et al. (2009) was able to reduce heterogeneity; however, this exclusion did not change the association with DKD. Therefore, we could not fully exclude the possibility that the heterogeneity observed might reduce our power to detect true associations.

Despite these negative results regarding associations between $U C P 2$ polymorphisms and $\mathrm{DKD}$, functional studies have suggested that changes in $U C P 2$ expression play an important role in the development of renal damage. Qiu et al. (2012) reported that oral administration of genipin, a UCP2 inhibitor, partially prevented the progression of DKD in C57BL/6J mice by reducing glucose-induced albumin leakage through podocyte monolayers, consequently improving podocyte function. Accordingly, Jiang et al. (2013) showed that UCP2 was induced in kidney tubular epithelial cells after unilateral ureteral obstruction in mice, while those mice with ablated $U C P 2$ resisted obstruction-induced kidney fibrosis. Moreover, UCP2 knockdown in NRK-52E tubular cells abolished the effect of TGF- $\beta 1$ treatment, decreasing extracellular matrix production (Jiang et al., 2013). In contrast, Chen et al. (2014) demonstrated that inhibition of UCP2 by genipin increased oxidative stress in rat proximal tubular cells treated with high glucose medium, and this led to increased cell apoptosis. UCP2 knockdown in renal mesangial cells of rats also increased oxidative stress, inflam- mation, and apoptosis in vitro (Di Castro et al., 2013). Therefore, whether UCP2 has a protective or deleterious effect in renal function remains to be clarified.

In conclusion, data reported here suggest that the $U C P 2$-866G/A and Ins/Del polymorphisms are not important risk factors for DKD, classified according to UAE values. Further additional studies with large sample sizes are necessary to elucidate the effects possibly played by $U C P 2$ polymorphisms in the pathogenesis of DKD.

\section{Acknowledgments}

This study was partially supported by grants from the Conselho Nacional de Desenvolvimento Científico e Tecnológico (CNPq), Fundo de Incentivo à Pesquisa e Eventos (FIPE) at Hospital de Clínicas de Porto Alegre (grant number: 2017-0095), Fundação de Amparo à Pesquisa do Estado do Rio Grande do Sul (FAPERGS), and Coordenação de Aperfeiçoamento de Pessoal de Nível Superior (CAPES Finance code 001). D.C. is a recipient of scholarships from CNPq, while N.E.L., C.D., T.A.S. and B.M.S. received scholarships from CAPES.

\section{Conflict of interest}

The authors declare no conflict of interest.

\section{Author contributions}

CD designed the study, researched the data, performed the experiments and the meta-analysis, and wrote the manuscript. TSA researched the data, contributed to discussion, and reviewed the manuscript. NEL researched the data, performed the meta-analysis, and reviewed the manuscript. ETM performed the experiments. ACB and BMS contributed to the discussion and reviewed the manuscript. DC designed the study, contributed to the discussion, and wrote the manuscript.

\section{References}

Ahlqvist E, van Zuydam NR, Groop LC and McCarthy MI (2015) The genetics of diabetic complications. Nat Rev Nephrol 11:277-287.

American Diabetes Association (2018) Classification and Diagnosis of Diabetes: Standards of Medical Care in Diabetes2018. Diabetes Care 41:S13-S27.

Assmann TS, Brondani AL, Bauer AC, Canani LH and Crispim D (2014) Polymorphisms in the TLR3 gene are associated with risk for type 1 diabetes mellitus. Eur J Endocrinol 170:519527.

Assmann TS, Recamonde-Mendoza M, Souza BM, Bauer AC and Crispim D (2018) MicroRNAs and diabetic kidney disease: Systematic review and bioinformatic analysis. Mol Cell Endocrinol 477:90-102.

Boucas AP, Brondani LA, Souza BM, Lemos NE, Oliveira FS, Canani LH and Crispim D (2013) The A allele of the rs1990760 polymorphism in the IFIH1 gene is associated with protection for arterial hypertension in type 1 diabetic 
patients and with expression of this gene in human mononuclear cells. PLoS One 8:e83451.

Brondani LA, Assmann TS, Souza BM, Boucas AP, Canani LH and Crispim D (2014) Meta-analysis reveals the association of common variants in the uncoupling protein (UCP) 1-3 genes with body mass index variability. PLoS One 9:e96411.

Brownlee M (2005) The pathobiology of diabetic complications: A unifying mechanism. Diabetes 54:1615-1625.

Camargo JL, Zelmanovitz T, Paggi A, Friedman R and Gross JL (1998) Accuracy of conversion formulae for estimation of glycohaemoglobin. Scand J Clin Lab Invest 58:521-528.

Carpena MP, Rados DV, Sortica DA, Souza BM, Reis AF, Canani LH and Crispim D (2010) Genetics of diabetic nephropathy. Arq Bras Endocrinol Metabol 54:253-261.

Cassell PG, Neverova M, Janmohamed S, Uwakwe N, Qureshi A, McCarthy MI, Saker PJ, Albon L, Kopelman P, Noonan K et al. (1999) An uncoupling protein 2 gene variant is associated with a raised body mass index but not Type II diabetes. Diabetologia 42:688-692.

Chai Y, Gu B, Qiu JR, Yi HG, Zhu Q, Zhang L and Hu G (2012) The uncoupling protein $2-866 \mathrm{G}>$ a polymorphism is associated with the risk of ischemic stroke in Chinese type 2 diabetic patients. CNS Neurosci Ther 18:636-640.

Chen XL, Tang WX, Tang XH, Qin W and Gong M (2014) Downregulation of uncoupling protein-2 by genipin exacerbates diabetes-induced kidney proximal tubular cells apoptosis. Ren Fail 36:1298-1303.

Crispim D, Fagundes NJ, Santos KG, Rheinheimer J, Boucas AP, Souza, Macedo GS, Leiria LB, Gross JL and Canani LH (2010) Polymorphisms of the UCP2 gene are associated with proliferative diabetic retinopathy in patients with diabetes mellitus. Clin Endocrinol 72:612-619.

Dalgaard LT (2011) Genetic variance in uncoupling protein 2 in relation to obesity, type 2 diabetes, and related metabolic traits: focus on the functional $-866 \mathrm{G}>$ a promoter variant (rs659366). J Obes 2011:340241.

de Souza BM, Assmann TS, Kliemann LM, Marcon AS, Gross JL, Canani LH and Crispim D (2012) The presence of the $-866 \mathrm{~A} / 55 \mathrm{Val} / \mathrm{Ins}$ haplotype in the uncoupling protein 2 (UCP2) gene is associated with decreased UCP2 gene expression in human retina. Exp Eye Res 94:49-55.

de Souza BM, Brondani LA, Boucas AP, Sortica DA, Kramer CK, Canani LH, Leitao CB and Crispim D (2013) Associations between UCP1 -3826A/G, UCP2 -866G/A, Ala55Val and Ins/Del, and UCP3 -55C/T polymorphisms and susceptibility to type 2 diabetes mellitus: case-control study and metaanalysis. PLoS One 8:e54259.

de Souza BM, Michels M, Sortica DA, Boucas AP, Rheinheimer J, Buffon MP, Bauer AC, Canani LH and Crispim D (2015) Polymorphisms of the UCP2 gene are associated with glomerular filtration rate in type 2 diabetic patients and with decreased UCP2 gene expression in human kidney. PLoS One 10:e0132938.

Di Castro S, Scarpino S, Marchitti S, Bianchi F, Stanzione R, Cotugno M, Sironi L, Gelosa P, Duranti E, Ruco L et al. (2013) Differential modulation of uncoupling protein 2 in kidneys of stroke-prone spontaneously hypertensive rats under high-salt/low-potassium diet. Hypertension 61:534-541.
Donadelli M, Dando I, Fiorini C and Palmieri M (2014) UCP2, a mitochondrial protein regulated at multiple levels. Cell Mol Life Sci 71:1171-1190.

Du XL, Edelstein D, Rossetti L, Fantus IG, Goldberg H, Ziyadeh F, Wu J and Brownlee M (2000) Hyperglycemia-induced mitochondrial superoxide overproduction activates the hexosamine pathway and induces plasminogen activator inhibitor-1 expression by increasing Sp1 glycosylation. Proc Natl Acad Sci U S A 97:12222-12226.

Esterbauer H, Schneitler C, Oberkofler H, Ebenbichler C, Paulweber B, Sandhofer B, Ladurner G, Hell E, Strosberg AD, Patsch JR et al. (2001) A common polymorphism in the promoter of UCP2 is associated with decreased risk of obesity in middle-aged humans. Nat Genet 28:178-183.

Giacco F and Brownlee M (2010) Oxidative stress and diabetic complications. Circ Res 107:1058-1070.

Gross JL, Azevedo MJ, Silveiro SP, Canani LH, Caramori ML and Zelmanovitz T (2005) Diabetic nephropathy: diagnosis, prevention, and treatment. Diabetes Care 28:164-176.

Hedrick PW (1987) Gametic disequilibrium measures: proceed with caution. Genetics 117:331-341.

Higgins JP and Thompson SG (2002) Quantifying heterogeneity in a meta-analysis. Stat Med 21:1539-1558.

Higgins JP, Thompson SG, Deeks JJ and Altman DG (2003) Measuring inconsistency in meta-analyses. BMJ 327:557-560.

Ji Q, Ikegami H, Fujisawa T, Kawabata Y, Ono M, Nishino M, Ohishi M, Katsuya T, Rakugi H and Ogihara T (2004) A common polymorphism of uncoupling protein 2 gene is associated with hypertension. J Hypertens 22:97-102.

Jia JJ, Zhang X, Ge CR and Jois M (2009) The polymorphisms of UCP2 and UCP3 genes associated with fat metabolism, obesity and diabetes. Obes Rev 10:519-526.

Jiang L, Qiu W, Zhou Y, Wen P, Fang L, Cao H, Zen K, He W, Zhang C, Dai C et al. (2013) A microRNA-30e/mitochondrial uncoupling protein 2 axis mediates TGF-betal-induced tubular epithelial cell extracellular matrix production and kidney fibrosis. Kidney Int 84:285-296.

Kanwar YS, Sun L, Xie P, Liu FY and Chen S (2011) A glimpse of various pathogenetic mechanisms of diabetic nephropathy. Annu Rev Pathol 6:395-423.

Katsarou A, Gudbjornsdottir S, Rawshani A, Dabelea D, Bonifacio E, Anderson BJ, Jacobsen LM, Schatz DA and Lernmark A (2017) Type 1 diabetes mellitus. Nat Rev Dis Primers 3:17016.

KDIGO Group (2013) KDIGO 2012 Clinical practice guideline for the evaluation and management of chronic kidney disease. Kidney Int 3:1-150.

Lahiri DK and Nurnberger Jr JI (1991) A rapid non-enzymatic method for the preparation of HMW DNA from blood for RFLP studies. Nucleic Acids Res 19:5444.

Levey AS, Stevens LA, Schmid CH, Zhang YL, Castro AF 3rd, Feldman HI, Kusek JW, Eggers P, Van Lente F, Greene T et al. (2009) A new equation to estimate glomerular filtration rate. Ann Intern Med 150:604-612.

Lindholm E, Klannemark M, Agardh E, Groop L and Agardh CD (2004) Putative role of polymorphisms in UCP1-3 genes for diabetic nephropathy. J Diabetes Complications 18:103-107.

Little J, Higgins JP, Ioannidis JP, Moher D, Gagnon F, von Elm E, Khoury MJ, Cohen B, Davey-Smith G, Grimshaw J et al. (2009) Strengthening the Reporting of Genetic Association 
Studies (STREGA) - an extension of the STROBE statement. Genet Epidemiol 33:581-598.

Macisaac RJ, Ekinci EI and Jerums G (2014) Markers of and risk factors for the development and progression of diabetic kidney disease. Am J Kidney Dis 63:S39-62.

Minelli C, Thompson JR, Abrams KR, Thakkinstian A and Attia J (2005) The choice of a genetic model in the meta-analysis of molecular association studies. Int J Epidemiol 34:1319-1328.

Moher D, Liberati A, Tetzlaff J, Altman DG and Group P (2009) Preferred reporting items for systematic reviews and metaanalyses: the PRISMA statement. BMJ 339:b2535.

Oberkofler H, Dallinger G, Liu YM, Hell E, Krempler F and Patsch W (1997) Uncoupling protein gene: Quantification of expression levels in adipose tissues of obese and non-obese humans. J Lipid Res 38:2125-2133.

Qiu W, Zhou Y, Jiang L, Fang L, Chen L, Su W, Tan R, Zhang CY, Han X and Yang J (2012) Genipin inhibits mitochondrial uncoupling protein 2 expression and ameliorates podocyte injury in diabetic mice. PLoS One 7:e41391.

Rich SS (2006) Genetics of diabetes and its complications. J Am Soc Nephrol 17:353-360.

Ritz E, Zeng XX and Rychlik I (2011) Clinical manifestation and natural history of diabetic nephropathy. Contrib Nephrol 170:19-27.

Rudofsky Jr G, Schroedter A, Schlotterer A, Voron'ko OE, Schlimme M, Tafel J, Isermann BH, Humpert PM, Morcos M, Bierhaus A et al. (2006) Functional polymorphisms of $\mathrm{UCP} 2$ and UCP3 are associated with a reduced prevalence of diabetic neuropathy in patients with type 1 diabetes. Diabetes Care 29:89-94.

Rudofsky Jr G, Schrodter A, Voron'ko OE, Schlotterer A, Humpert PM, Tafel J, Nawroth PP, Bierhaus A and Hamann A (2007) Promoter polymorphisms of UCP1, UCP2, and UCP3 are not associated with diabetic microvascular complications in type 2 diabetes. Horm Metab Res 39:306-309.

Ruggenenti P and Remuzzi G (2000) Nephropathy of type 1 and type 2 diabetes: Diverse pathophysiology, same treatment? Nephrol Dial Transplant 15:1900-1902.

Scheffel RS, Bortolanza D, Weber CS, Costa LA, Canani LH, Santos KG, Crispim D, Roisenberg I, Lisboa HR, Tres GS et al. (2004) Prevalence of micro and macroangiopatic chronic complications and their risk factors in the care of out patients with type 2 diabetes mellitus. Rev Assoc Med Bras 50:263-267.

Souza BM, Assmann TS, Kliemann LM, Gross JL, Canani LH and Crispim D (2011) The role of uncoupling protein 2 (UCP2) on the development of type 2 diabetes mellitus and its chronic complications. Arq Bras Endocrinol Metabol 55:239-248.

Stang A (2010) Critical evaluation of the Newcastle-Ottawa scale for the assessment of the quality of nonrandomized studies in meta-analyses. Eur J Epidemiol 25:603-605.

Stephens M, Smith NJ and Donnelly P (2001) A new statistical method for haplotype reconstruction from population data. Am J Hum Genet 68:978-989.

Stroup DF, Berlin JA, Morton SC, Olkin I, Williamson GD, Rennie D, Moher D, Becker BJ, Sipe TA and Thacker SB (2000)
Meta-analysis of observational studies in epidemiology: A proposal for reporting. Meta-analysis Of Observational Studies in Epidemiology (MOOSE) group. JAMA 283:2008-2012.

Thomas MC, Brownlee M, Susztak K, Sharma K, Jandeleit-Dahm KA, Zoungas S, Rossing P, Groop PH and Cooper ME (2015) Diabetic kidney disease. Nat Rev Dis Primers 1:15018.

Tiwari AK, Prasad P, B K T, Kumar KM, Ammini AC, Gupta A and Gupta R (2009) Oxidative stress pathway genes and chronic renal insufficiency in Asian Indians with type 2 diabetes. J Diabetes Complications 23:102-111.

Toda C and Diano S (2014) Mitochondrial UCP2 in the central regulation of metabolism. Best Pract Res Clin Endocrinol Metab 28:757-764.

Tripathi G, Sharma RK, Baburaj VP, Sankhwar SN, Jafar T and Agrawal S (2008) Genetic risk factors for renal failure among north Indian ESRD patients. Clin Biochem 41:525-531.

von Elm E, Altman DG, Egger M, Pocock SJ, Gotzsche PC, Vandenbroucke JP and Initiative S (2008) The Strengthening the Reporting of Observational Studies in Epidemiology (STROBE) statement: Guidelines for reporting observational studies. J Clin Epidemiol 61:344-349.

Wang H, Chu WS, Lu T, Hasstedt SJ, Kern PA and Elbein SC (2004) Uncoupling protein-2 polymorphisms in type 2 diabetes, obesity, and insulin secretion. Am J Physiol Endocrinol Metab 286:E1-7.

Yu X, Wieczorek S, Franke A, Yin H, Pierer M, Sina C, Karlsen TH, Boberg KM, Bergquist A, Kunz M et al. (2009) Association of UCP2 -866 G/A polymorphism with chronic inflammatory diseases. Genes Immun 10:601-605.

Zelmanovitz T, Gross JL, Oliveira JR, Paggi A, Tatsch M and Azevedo MJ (1997) The receiver operating characteristics curve in the evaluation of a random urine specimen as a screening test for diabetic nephropathy. Diabetes Care 20:516-519.

\section{Supplementary material}

The following online material is available for this article:

MeSH terms used for searching articles to be included in meta-analysis.

Table S1 - Genotype and allele frequencies of UCP2 $-866 \mathrm{G} / \mathrm{A}$ and Ins/Del polymorphisms. in T1DM patients.

Table S2 - Genotype and allele frequencies of UCP2 $-866 \mathrm{G} / \mathrm{A}$ and Ins/Del polymorphisms in T1DM patients and in nondiabetic subjects.

Table S3 - Genotype and allele distributions of the UCP2 $-866 \mathrm{G} / \mathrm{A}$ and Ins/Del polymorphisms in T1DM patients with (cases) and without (controls) DKD.

Associate Editor: Luiz F.Z. Batista

License information: This is an open-access article distributed under the terms of the Creative Commons Attribution License (type CC-BY), which permits unrestricted use, distribution and reproduction in any medium, provided the original article is properly cited. 